\section{DIGESTIBILIDADE (APARENTE) E PRODUÇĀO FORRAGEIRA DE UM PASTO DE CAPIM GORDURA (MELINIS MINUTIFLORA, PAL DE BEAUV). FASE II. PERIODO DE INVERNO}

\author{
LICIO VELLOSO \\ Professor Adjunto \\ Faculdade de Medicina Veterinária \\ e Zootecnia da USP \\ MAURO PROCKNOR \\ Médico Veterinário \\ Instituto de Zootecnia \\ WALDEMAR STRAZZACAPPA \\ Diretor Técnico \\ Boiúna Agropecuária S.A. \\ KIYOMI SEKI \\ Estagiário \\ Faculdade de Medicina Veterinária \\ e Zootecnia da USP \\ GODOFREDO MILTENBURG \\ Estagiário \\ Faculdade de Medicina Veterinária \\ e Zootecnia da USP
}

VELLOSO, L.; PROCKNOR, M.; STRAZZACAPPA, W.; SEKI, K.; MILTENBURG, G. Digestibilidade (aparente) e produção forrageira de um pasto de capim gordura (Melinis minutiflora, Pal de Beauv). Fase II. Período de inverno. Rev.Fac.Med.vet.Zootec.Univ.S.Paulo, 19(1): 87-95, 1982.

RESUMO: A planta forrageira estudáa toi proveniente de um pasto com árca de 2,0 ha, formado em setembro de 1974 , tendo recebido antes da semeadura uma aplicação de $1.700 \mathrm{~kg} / \mathrm{ha}$ de calcáreo dolomítico e, após o plantio $510 \mathrm{~kg} /$ ha de sulfato de amônio. A partir de sua formação foi utilizado em pastejo rotacionado por vacas em lactação, até o dia 27 de setembro de 1977, quando foi efetuado um corte com roçadeira para padronização, visando o aproveitamento da rebrota para os estudos conduzidos. Os ensaios de digestibilidade e as estimativas de produção forrageira foram efetuados em média aos 240,300 e 360 dias de idade do capim. Os dados de produção da forragem foram obtidos com doze amostras colhidas com o auxilio de um quadrado de ferro medindo $0,25 \mathrm{~m}^{2}$, tendo sido observados os seguintes resultados: 1) aos 240 dias (29/09/77 a 26/05/78): $37.430 \mathrm{~kg} / \mathrm{ha}$ de massa verde (MV) e $13.870 \mathrm{~kg} / \mathrm{ha}$ de matéria seca (MS). 2) aos 300 dias (27/09/77 a 25/07/78): $20.930 \mathrm{~kg} / \mathrm{ha} \mathrm{de} \mathrm{MV} \mathrm{e}$ $10.360 \mathrm{~kg} / \mathrm{ha}$ de MS. 3 ) aos 360 dias $(27 / 09 / 77$ a $23 / 09 / 78): 15.200$ $\mathrm{kg} / \mathrm{ha}$ de MV e $9.060 \mathrm{~kg} / \mathrm{ha}$ de MS. Os ensaios de digestibilidade (aparente) foram efetuados com três bovinos em gaiolas e os valores dos nutrientes digestíveis na MS a $100^{\circ} \mathrm{C}$ foram: 1) aos 240 dias: matéria seca digestível $(\mathrm{MSD})=12,7 \%$; proteina digestivel $(\mathrm{PD}) \stackrel{\text { : }}{=}$ zero; extrato etéreo digestível (EED) $=3,3 \%$; fibra digestível (FD) $=209 \%$; extrativos năo nitrogenados digestiveis (ENND) $=20,4 \%$ e nutrientes digestíveis totais (NDT) $=44.6 \%$. 2) aos 300 dias: $\mathrm{MSD}$ $=16,2 \% ; \mathrm{PD}=$ zero; $\mathrm{EED}=2.4 \% ; \mathrm{FD}=22,8 \% ; \mathrm{ENND}=18,5 \% \mathrm{e}$ $\mathrm{NDT}=43,7 \%, 3)$ aos 360 dias: $\mathrm{MSD}=26,1 ; \mathrm{PD}=$ zero $; \mathrm{EED}=$ $0,7 \% ; \mathrm{FD}=23,8 \%$; ENND $=20,0 \%$ e NDT $=44,5$. Os valores de EED foram multiplicados pelo fator 2,25 .

UNITERMOS : Alimentos, digestibilidade* ; Capim gordura*; Forrageiras, produção*

\section{INTRODUÇÃO}

O capim gordura (Melinis minutiflora, Pal de Beauv) tem apresentado uma notável importância na produção leiteira do Brasil, principalmente nas faixas de clima mais ameno dos estados da região. Sudeste. Dessa forma, o conhecimento de suas potencialidades, tanto em termos quantitativos como qualitativos, assume papel fundamental na continuidade de sua utilizaçăo numa pecuária a qual tende a se tornar cada vez mais técnica, portanto, mais exigente.

Durante a Fase I - Período de verăo, desse experimento, VELLOSO e cols 12 verificaram que o capim gordura produziu aos 180 dias de idade, $11.480 \mathrm{~kg} / \mathrm{ha}$ de matéria seca, porém, seu melhor valor nutritivo foi captado aos 120 dias de idade quando apresentou teor de nutrientes digestí veis totais de $57,1 \%$ e um coeficiente médio de digestibilidade da matéria seca da ordem de $56,5 \%$.

COELHO DA SILVA e GOMIDE 4 , ao estudarem o efeito da maturação sobre o consumo e a digestibilidade aparente da matéria seca de três gramíneas tropicais, verificaram que o capim gordura apresentou decréscimo de 0,17 unidades mensais no consumo de matéria seca à medida que a idade do capim aumentou de dois até oito meses. A digestibilidade da matéria seca apresentou coeficientes médios que variaram de um máximo de $59,5 \%$ aos dois meses até $40,2 \%$ aos oito meses de idade da planta. Os teores médios de matéria seca digestível foram: $13,1 \%$ aos dois meses; $15,1 \%$ aos quatro meses, $16,7 \%$ aos seis meses e $17,9 \%$ aos oito meses de idade.

Trabalho igualmente interessante foi o desenvolvido por PAULA e cols 8 os quais estudaram a influência de diferentes sistemas de corte sobre o desenvolvimento radicular do capim gordura, tendo concluído que o melhor desenvolvimento radicular do capim gordura foi observado quando o mesmo foi ceifado a vinte e dois centímetros do solo e também quando os intervalos entre os cortes foram maiores (oito semanas).

GOIS MENDONÇA e NASCIMENTO JR.5, estudando a composição química de sete forrageiras tropicais, em quatro estádios de maturação, e tendo o capim gordura entre elas, concluíram que a diferença de trinta e cinco dias entre cortes, após as forrageiras terem alcançado maturidade elevada, não modificou os teores de matéria seca e proteina bruta.

ROCHA 10 , visando estabelecer os coeficientes de digestibilidade do capim gordura, através do ano, obteve indices de proteína digestível que variaram de 5,8\% (janeiro) até $0,6 \%$ (julho) demonstrando claramente as modificaçðes que ocorrem na digestibilidade dessa espécie forrageira, desde o auge do seu estádio de vegetação até após o florescimento. Observou ainda o autor que, no periodo de outubro a março (150 dias de verão) o capim gordura forneceu $66 \%$ da produção anual de matéria seca enquanto que de março a outubro (215 dias de inverno) foram produzidos os $34 \%$ 
restantes, sendo $22,1 \%$ no início do período seco (março a junho) e $11,9 \%$ no final do período seco (julho a outubro).

PLUT e MELOTTI ${ }^{9}$ analisando os teores de lignina e de outros componentes químicos nos capins jaraguá e gordura, observaram que no capim gordura ocorreu um decréscimo no teor de proteína bruta e um aumento nos teores de fibra bruta sendo que a fração lignina não apresentou variaçбes apreciáveis a partir do segundo estádio de crescimento, dentre os sete estádios estudados.

ANDREASI e cols 1 , realizando um levantamento da composição bromatológica de plantas forrageiras oriundas de áreas delimitadas no Estado de São Paulo, obtiveram valores médios de $6,2 \%$ de proteína bruta na época chuvosa e de $4,6 \%$ durante o período seco enquanto que as porcentagens de fibra bruta situaram-se em $36,6 \%$ no inverno e em $34,1 \%$ durante o verão. Salientam ainda os autores que, durante o período seco, o teor de prote ína bruta em qualquer das três gramíneas estudadas (colonião, jaraguá e gordura) mostrou-se acentuadamente deficitário para atender as exigências dos bovinos criados exclusivamente em pastoreio.

Visando realizar uma estimativa dos teores de matéria seca e proteína bruta no feno de capim gordura sob diferentes processos de fenação e armazenamento, CARVALHO e cols $^{3}$, realizaram um ensaio, com a mencionada gramínea ceifada em duas épocas diferentes, sendo a primeira cerca de 40 dias antes da floração e a segunda no início do florescimento. $\mathrm{O}$ feno produzido utilizando-se as plantas mais jovens apresentou teores de matéria seca $(66 \%)$ e proteína bruta $(5,0 \%)$ mais elevados do que o feno proveniente do segundo corte, cujos teores foram de $60,4 \%$ e $3,5 \%$ respectivamente para a matéria seca e para a proteína bruta. Relatam ainda os autores que feno produzido, de maneira geral, apresentou teores médios de $63,3 \%$ para a matéria seca e de $4,3 \%$ para a proteina bruta.

Também ROCHA (citado por JARDIM6) encontrou uma queda acentuada nos teores de proteína bruta do feno de capim gordura entre os cortes efetuados com a gramínea em estádio inicial de crescimento (janeiro) de $5,79 \%$ e os estádios de floração (junho) $5,02 \%$ e de pós-floração (julho) $3,04 \%$.

\section{MATERIAL E MÉTODOS}

A forragem utilizada no presente estudo, foi proveniente de uma pastagem formada em setembro de 1974, numa área aproximadamente 2,0 hectares existentes no Centro Intraunidade de Zootecnia e Indústrias Pecuárias "Fernando Costa" (CIZIP), pertencente à Faculdade de Medicina Veterinária e Zootecnia da Universidade de São Paulo, localizado em Pirassununga SP. O município situa-se na latitude 21059 'S e longitude $47059^{\prime} \mathrm{W}$, com altitude de $634 \mathrm{~m}$. O clima característico da região e o Cwa, na classificação Koppen, portanto úmido mesotermal de inverno seco e verão quente e chuvoso. As médias anuais de temperaturas e precipitação pluviométrica foram $20,8^{\circ}$ e $1.245 \mathrm{~mm}$, no período de janeiro de 1975 a dezembro de 1977 . O solo da área experimental é típicamente caracterizado como latossolo vermelho-escuro orto.

Dentre os preparativos para a formação da pastagem foi realizada a correção da acidez do solo com a aplicação de $1.700 \mathrm{~kg} / \mathrm{ha}$ de calcáreo dolomítico e, posteriormente, uma adubação por cobertura com sulfato de amônio à razão de $510 \mathrm{~kg} / \mathrm{ha}$. Desde a sua formação até o início do ensaio, a pastagem foi utilizada por vacas em lactação, num sistema de pastejo rotacionado.

Ao início dos trabalhos foi realizado corte de padronização no periodo de entrada das chuvas (setembro de 1977). Portanto, esta pastagem representa a média predominante na região.

As amostras para medir a disponibilidade de forragem, foram colhidas sempre às 13:00 horas, coincidindo com o $1^{\circ}, 4^{\circ}$ e $7^{\circ} \mathrm{dia}$, do respectivo período experimental. Cada amostra era constituída de quatro sub-amostras aleatórias, obtidas com o auxílio de um quadrado de ferro medindo $0,25 \mathrm{~m}^{2}$, sendo colhido todo o material acima de cinco centímetros do solo existente nessa área. $\mathrm{O}$ material assim coletado foi pesado para estimativa da produção de massa-verde e posteriormente, transferido para estufa a $70^{\circ}$ $C$ (com ventilação forçada) para determinação da produção de matéria seca por unidade de área.

Para os ensaios de digestibilidade aparentes, adotaram-se técnicas recomendadas por SCHNEIDER e FLATT ${ }^{1}{ }^{1}$, com a coleta total das fezes, sendo que o dia intermediário de cada período correspondeu as $240^{\circ}, 300^{\circ} \mathrm{e}$ $360^{\circ}$ dia, à partir do corte de padronização.

Seguindo o que preconizaram McDONALD e cols 7 foram utilizados trếs bovinos mestiços Holandês vs Zebú, machos inteiros, com cerca de dois anos de idade no início do ensaio os quais passaram por período de adaptação ao capim gordura, durante oito dias. Posteriormente foram levados às gaiolas de digestibilidade, nas quais permaneceram por dez dias; sendo os três primeiros para adaptação e os sete restantes para efeito experimental.

O capim foi ceifado duas vezes ao dia (manhã e tarde), simulando o pastejo e, após fracionado numa picadora de lâminas e pesado, foi fomecido aos animais nas gaiolas, à vontade. Ainda foi fornecido a cada animal, diariamente cerca de 30 gramas de mistura mineral completa.

Para determinação da matéria seca do capim fornecido, das sobras e das fezes, realizaram-se amostragens diárias, sendo que para o capim oferecido e para as sobras foram cothidas pela manhã e à tarde, visando captar variaçōes no teor de matéria seca dentro do mesmo dia. Após secadas em estufa, a $100{ }^{\circ} \mathrm{C}$, as amostras foram moídas em moinho Thomas Wiley Model $4 \mathrm{com}$ peneiras de $1 \mathrm{~mm}$ e estocadas em frascos de polietileno, até a ocasião das análises bromatológicas, segundo métodos do A.O.A.C. ${ }^{2}$, excessão feita aos extrativos nฮ̃o nitrogenados, obtidos por diferenças. 
Digestibilidade (aparente) e produção forrageira de um pasto de capim gordura (Melinis minutiflora, Pal de Beauv). Fase II. Período de inverno.

\section{RESULTADOS E DISCUSSÃO}

As análises químico-bromatológicas realizadas no capim gordura aos 240,300 e 360 dias de idade, revelaram que os teores de matéria seca aumentaram com o avanço da idade do capim, contrariando afirmação de GOIS MENDONÇA e NASCIMENTO JR. ${ }^{5}$ para os quais, após a maturação da planta forrageira, já não ocorre modificação que mereça registro no teor de matéria seca. Por outro lado os teores de extrato etéreo cairam de $2,9 \%$ para $2,3 \%$ e finalmente para $1,6 \%$, nos três períodos experimentais. Com relação à proteína bruta, fibra bruta, extrativos não nitrogenados e à matéria mineral, nđo foram constatadas variaçðes consideráveis, em função da idade do capim, durante o período de inverno, isto é, de maio a setembro, concordando com dados de GOIS MENDONÇA e NASCIMENTO JR. ${ }^{5}$ no que respeita à proteína bruta (Tabela 1 ).

TABELA 1 - Variação na composição química do capim gordura nos três períodos experimentais $(240,300$ e 360 dias de idade) durante o inverno. Resultados na matéria seca a $100^{\circ} \mathrm{C}$.

\begin{tabular}{lccccccc}
$\begin{array}{l}\text { Idade do } \\
\text { capim }\end{array}$ & Período & $\begin{array}{c}\text { M.S. } \\
\%\end{array}$ & $\begin{array}{c}\text { P.B. } \\
\%\end{array}$ & $\begin{array}{c}\text { E.E. } \\
\%\end{array}$ & $\begin{array}{c}\text { F.B. } \\
\%\end{array}$ & $\begin{array}{c}\text { E.N.N. } \\
\%\end{array}$ & $\begin{array}{c}\text { M.M. } \\
\%\end{array}$ \\
\hline 240 dias & $\begin{array}{l}27 / 09 / 77 \\
26 / 05 / 78\end{array}$ & 29,50 & 3,00 & 2,90 & 43,40 & 44,90 & 5,70 \\
\multirow{2}{*}{300 dias } & $\begin{array}{l}27 / 09 / 77 \\
25 / 07 / 78\end{array}$ & 40,10 & 2,40 & 2,30 & 43,90 & 45,50 & 5,90 \\
\multirow{2}{*}{360 dias } & $\begin{array}{l}27 / 09 / 77 \\
23 / 09 / 78\end{array}$ & 61,10 & 2,90 & 1,60 & 45,30 & 44,60 & 5,60 \\
\hline
\end{tabular}

M.S. = matéria seca; P.B. = proteína bruta; E.E. = extrato etéreo; F.B. = fibra bruta; E.E.N. = extrativos não nitrogenados; M.M. = matéria mineral.

Saliente-se que dados comparativos do verão com os do inverno, geralmente apresentam queda no teor de prote ína bruta e elevação nos teores de matéria seca e de fibra bruta, como ocorreram nos trabalhos de PLUTT e MELOT$\mathrm{TI}^{9}$ e de ANDREASI e cols ${ }^{1}$; porém, considerando apenas' o período de seca, não foram verificadas variações dignas de registro, para estes nutrientes, desde os 240 até os 360 dias. de idade do capim. Quanto aos coeficientes de digestibilidade (CD), foram também constatadas poucas variaçðes após os 240 dias de idade, tanto para a MS quanto para FB e
ENN. Entretanto, COELHO DA SILVA e GOMIDE4, verificaram que houve redução no $\mathrm{CD}$ da MS de capim gordura entre dois e oito meses de idade (variando de $59,5 \%$ até $40,2 \%$ ). Houve redução no $\mathrm{CD}$ da fração de $\mathrm{EE}$, caindo de $51,2 \%$ aos 240 dias de idade para $18,6 \%$ aos 360 dias, sendo ‘significativa esta diferença à análise estatística. Finalmente a PB teve coeficiente zero de digestibilidade, durante o período de inverno (Tabela 2), próximo ao índice de $0,6 \%$ encontrado por ROCHA 10 , no mês de julho. 
TABELA 2 - Coeficientes médios de digestibilidade do capim gordura nos três períodos experimentais $(240,300$ e 360 dias de idade) durante o inverno. Resultados na matéria seca a $100^{\circ} \mathrm{C}$. (in vivo, obtidos com bovinos).

\begin{tabular}{|c|c|c|c|c|c|c|}
\hline $\begin{array}{l}\text { Idade do } \\
\text { capim }\end{array}$ & & $\begin{array}{c}\text { M.S. } \\
\%\end{array}$ & $\begin{array}{l}\text { P.B. } \\
\%\end{array}$ & $\begin{array}{c}\text { E.E. } \\
\%\end{array}$ & $\begin{array}{c}\text { F.B. } \\
\%\end{array}$ & $\begin{array}{c}\text { E.N.N. } \\
\%\end{array}$ \\
\hline 240 dias & $\begin{array}{c}x \\
s \\
\text { C.V. }\end{array}$ & $\begin{array}{c}43,19^{a} \\
0,94 \\
2,18\end{array}$ & $\begin{array}{c}\text { zero }^{\mathbf{a}} \\
- \\
-\end{array}$ & $\begin{array}{c}51,23^{\mathrm{a}} \\
1,79 \\
3,49\end{array}$ & $\begin{array}{c}48,14^{\mathrm{a}} \\
1,69 \\
3,51\end{array}$ & $\begin{array}{c}45,45^{\mathrm{a}} \\
1,20 \\
2,64\end{array}$ \\
\hline 300 dias & $\begin{array}{c}x \\
s \\
\text { C.V. }\end{array}$ & $\begin{array}{c}40,33^{\mathrm{a}} \\
4,17 \\
10,34\end{array}$ & $\begin{array}{c}\text { zero }^{\mathbf{a}} \\
- \\
-\end{array}$ & $\begin{array}{c}45,59^{\mathrm{a}} \\
5,64 \\
12,40\end{array}$ & $\begin{array}{c}52,01^{\mathrm{a}} \\
3,52 \\
6,77\end{array}$ & $\begin{array}{c}40,68^{\mathrm{a}} \\
6,02 \\
14,80\end{array}$ \\
\hline 360 dias & $\begin{array}{c}\mathbf{x} \\
\mathbf{s} \\
\text { C.V. }\end{array}$ & $\begin{array}{c}42,66^{\mathrm{a}} \\
2,93 \\
6,87\end{array}$ & $\begin{array}{c}\text { zero }^{\mathrm{a}} \\
- \\
-\end{array}$ & $\begin{array}{c}18,63^{b} \\
8,21 \\
44,07\end{array}$ & $\begin{array}{c}52,52^{\mathrm{a}} \\
2,15 \\
4,09\end{array}$ & $\begin{array}{c}44,82^{\mathrm{a}} \\
4,09 \\
9,13\end{array}$ \\
\hline
\end{tabular}

M.S. = matéria seca; P.B. = proteína bruta; E.E. = extrato etéreo; F.B. = fibra bruta; E.N.N. = extrativos não nitrogenados; $\mathrm{x}=$ média do período; $\mathrm{s}=$ desvio padráo; $\mathrm{C} . \mathrm{V} .=$ coeficiente de variação. Valores assinalados com letras iguais na mesma coluna não diferem entre si pelo teste de Tukey a $5 \%$.

As Figs. 1 e 2 ilustram bem os dados de consumo de alimento (MS) e a excreção de fezes (MS) durante os três períodos; além dos dados de produção e coeficiente de digestibilidade.

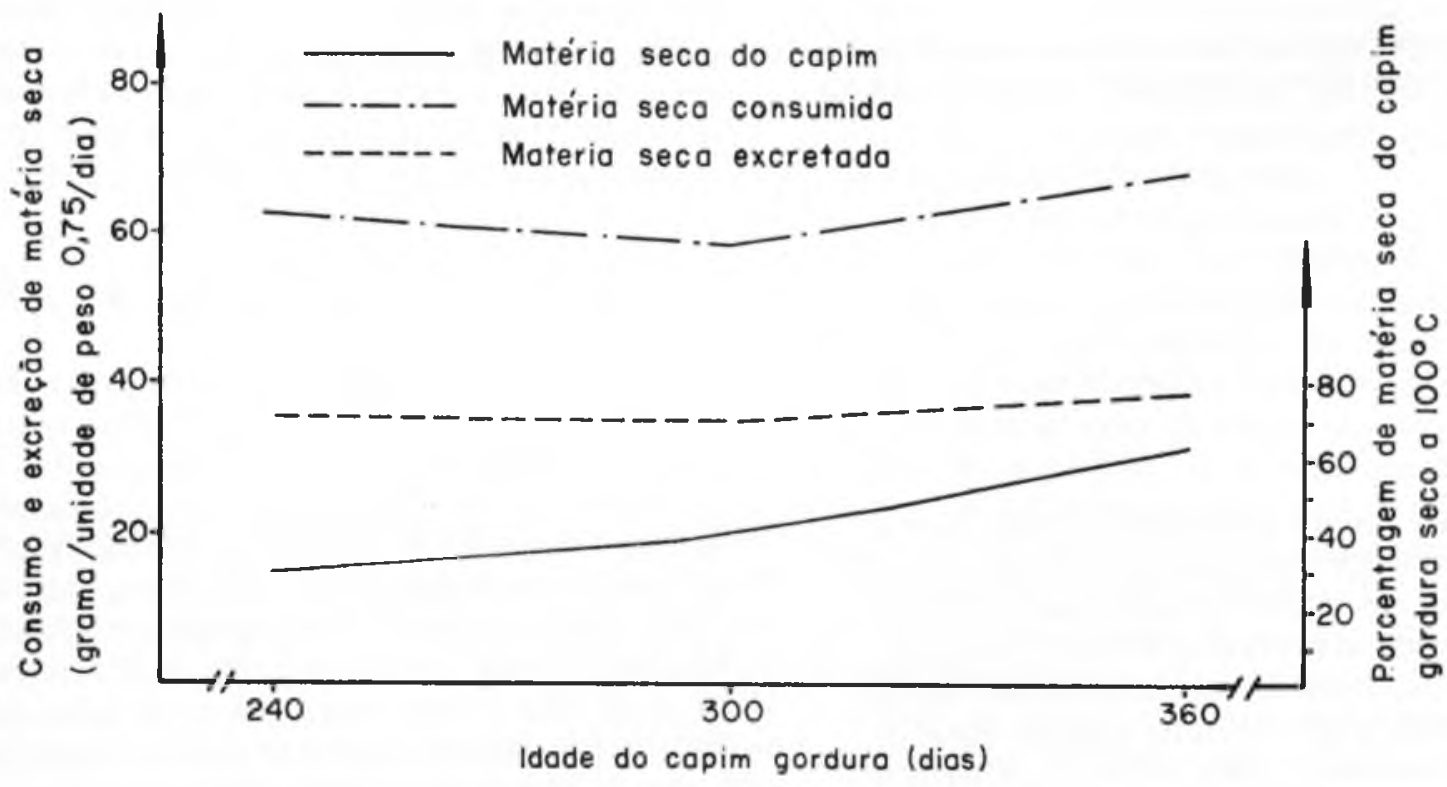

Fig.l - Curvos de materio seco consumida e excretada em reloçāo à matério seco do copim gorduro 


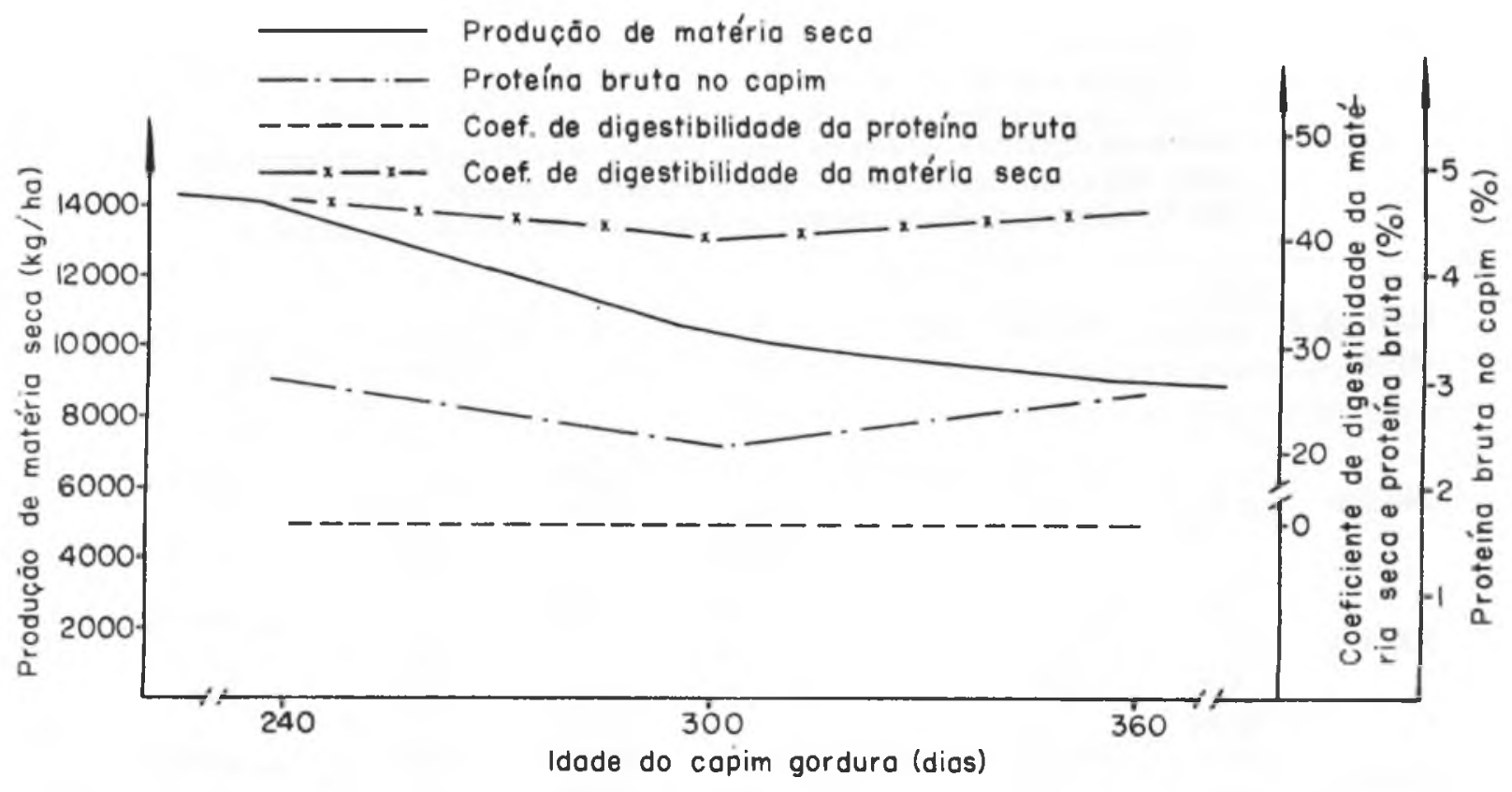

Fig. 2 - Curvas de produçao de matéria seca, digestibilidade da matério seco e do proteína bruta e o teor de proteína bruta no capim gordura

O capim gordura não apresenta praticamente qualquer valor como alimento, em termos de nutrientes digest iveis, quando deixado em crescimento contínuo até 300 dias de idade (Tabela 3 ). Contudo, 360 dias após corte de padroni :ação feito na primavera do ano anterior, já poderá ser no tado algum valor nutritivo no capim gordura, pois já há então, ocorrência de nova brotação, o que poderá ser constatado pela diferença estatística significativa detectada no teor de MS digest ível. $O$ baixo valor nutritivo do capim gordura durante o período de seca (junho/julho) já havia sido constatado por ROCHA 10 e também por ANDREASI e cols 1 . 
92 VELLOSO, L.; PROCKNOR, M.; STRAZZACAPPA, W.; SEKI, K.; MILTENBURG, G.

TABELA 3 - Nutrientes digestíveis médios do capim gordura nos três períodos experimentais ( 240,300 e 360 dias de idade) durante o inverno. Resultados na matéria seca a $100^{\circ} \mathrm{C}$ (calculados a partir da digestibilidade (aparente) obtida com bovinos).

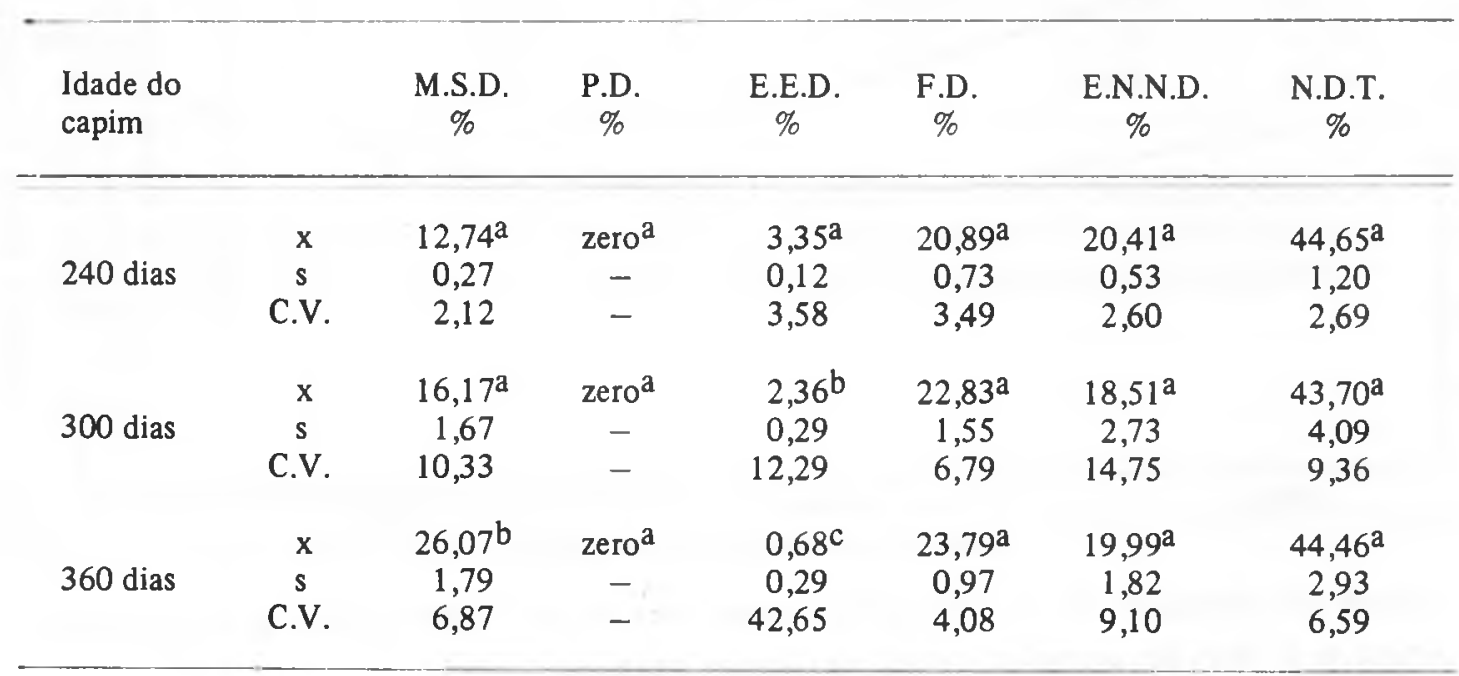

M.S.D. = matéria seca digestível; P.D. = proteína digestivel; E.E.D. = extrato etéreo digestível multiplicado pelo fator 2,25 para determinação dos nutrientes digestiveis totais; F.D. = fibra digestível; E.N.N.D. = extrativos ño nitrogenados digest íveis; N.D.T. $=$ nutrientes digest íveis to tais; $\mathrm{x}=$ média do período; $\mathrm{s}=$ desvio padrão; $C . V .=$ coeficiente de variação. Valores assinala . dos com letras iguais na mesma coluna nđo diferem entre si pelo teste de Tukey a $5 \%$.

Contrariando as diferenças observadas nos teores de nutrientes digestíveis, especialmente da MS, não ocorreu diferença estat ística significativa para consumo de MS, PD ou NDT, expressos em g/unidade de peso metabólico (Tabela
4), desde 240 até 360 dias de idade do capim gordura, cujos valores são inferiores àqueles encontrados por VELLOSO $\mathrm{e}$ cols 12 para a mesma gramínea, porém no período de verão, quando a idade do capim variou de 60 a 180 dias. 
Digestibilidade (aparente) e produção forrageira de um pasto de capim gordura (Melinis minutiflora, Pal de Beauv).

Fase II. Per íodo de inverno.

TABELA 4 - Consumos médios de matéria seca (M.S.), de proteína digestivel (P.D.) e nutrientes digestiveis totais (N.D.T.) nos três periodos experimentais $(240,300$ e 360 dias de idade) durante o inverno. Resultados na matéria seca a $100^{\circ} \mathrm{C}$.

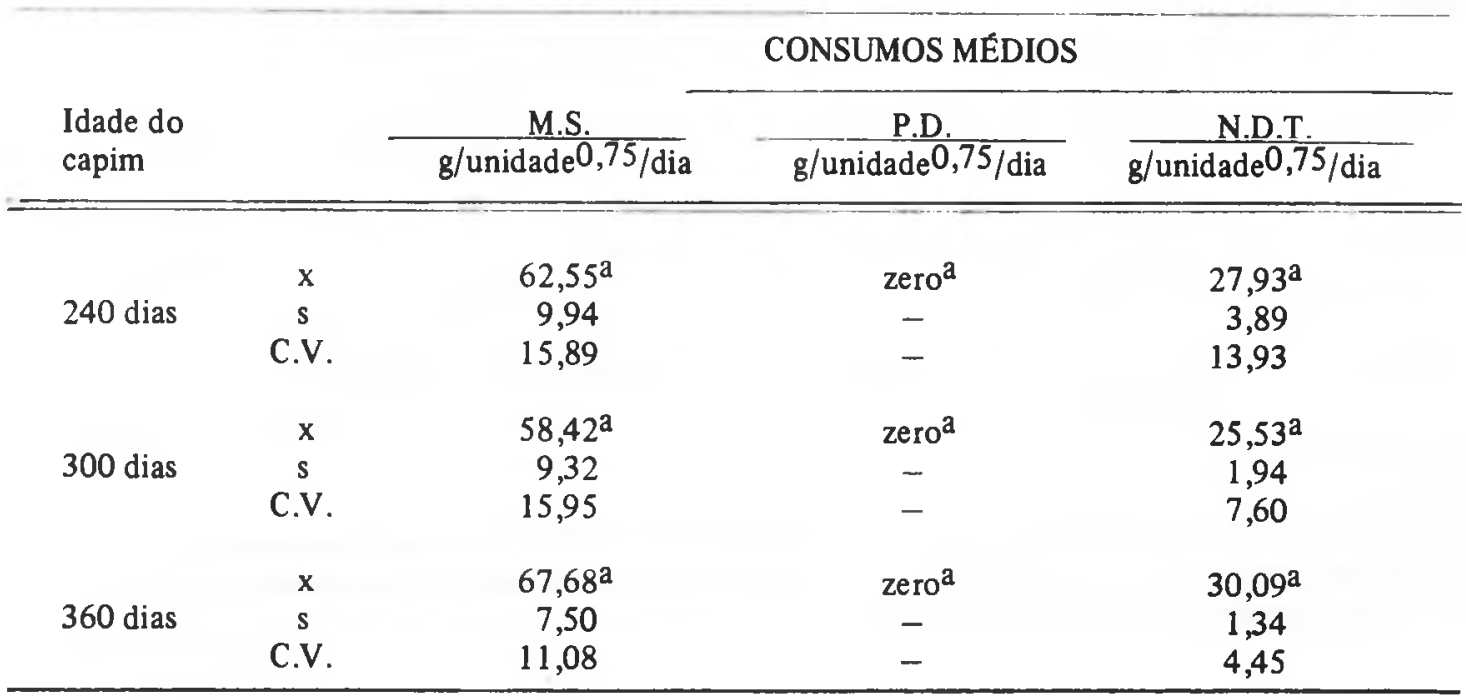

$x=$ média do período; $s=$ desvio padrão; $C . V .=$ coeficiente de variação. Valores assinalados com letras iguais na mesma coluna não diferem entre si pelo teste de Tukey a 5\%.

Finalmente, a Tabela 5 , mostra dados sobre produção de massa verde (MV) e de matéria seca (MS), expressos em $\mathrm{kg} / \mathrm{ha}$; onde é possível notar redução nas produçðes de MV e de MS, em decorrencia, principalmente da queda de folhas secas, fato muito comum no capim gordura maduro, no período de inverno seco, e observado com o avanço da idade do capim; nota-se que houve diferença estatística significativa tanto nas produçбes de MV quanto de MS entre 240 e 360 dias de idade. Estes dados estão muito próximos daquele encontrado por VELLOSO e cols 12 com o capim gordura aos 180 dias de idade. 
TABELA 5 - Estimativa de produção de massa verde (M.V.) e matéria seca (M.S.) a $70^{\circ} \mathrm{C}$ do capim gordura nos três períodos experimentais $(240,300$ e 360 dias de idade) durante o inverno.

\begin{tabular}{llllll}
\hline \multicolumn{5}{c}{} & \multicolumn{5}{c}{ PRODUÇÃo } \\
\hline $\begin{array}{l}\text { Idade do } \\
\text { capim }\end{array}$ & Período & $\begin{array}{l}\text { M.V. } \\
\mathrm{kg} / \mathrm{ha}\end{array}$ & $\begin{array}{l}\text { M.S. } \\
\mathrm{kg} / \mathrm{ha}\end{array}$ & $\begin{array}{l}\mathrm{S}(\mathrm{x}) \\
\mathrm{kg} / \mathrm{ha}\end{array}$ & $\begin{array}{c}\mathrm{C} . \mathrm{V} . \\
\%\end{array}$ \\
\hline 240 dias & $\begin{array}{l}27 / 09 / 77 \\
26 / 05 / 78\end{array}$ & $37.430^{\mathrm{a}}$ & $13.870^{\mathrm{a}}$ & 1.458 & 36,4 \\
& $\begin{array}{l}27 / 09 / 77 \\
300 \text { dias }\end{array}$ & $20.930^{\mathrm{b}}$ & $10.360^{\mathrm{ab}}$ & 1.011 & 33,8 \\
& $25 / 07 / 78$ & & & & \\
360 dias & $27 / 09 / 77$ & $15.200^{\mathrm{b}}$ & $9.060^{\mathrm{b}}$ & 730 & 27,9 \\
\hline
\end{tabular}

$\mathrm{S}(\mathrm{x})=$ erro-padrâo da média da produção de matéria seca a $70^{\circ} \mathrm{C} ; \mathrm{C} . \mathrm{V} .=$ coeficiente de variação da produção de matéria seca a $70^{\circ} \mathrm{C}$. Valores assinalados com letras iguais na mesma coluna não diferem entre si pelo teste de Tukey a $5 \%$.

\section{CONCLUSÕES}

O capim gordura (Melinis minutiflora, Pal de Beauv) revelou-se bastante deficiente em nutrientes e os seus coeficientes de digestibilidade pouco expressivos, (CDMS variando de $40,33 \%$ a $43,19 \%$ ) durante o período de inverno, quando em crescimento contínuo desde a primavera. Suas produçōes de massa verde (atingindo $37.430 \mathrm{~kg}$ ), e de matéria seca (atingindo $13.870 \mathrm{~kg}$ ). embora relativamente grandes, não têm condiçб̃es paraproporcionarem produção de carne ou de leite no período de seca em razão da sua baixa qualidade nutritiva, como ficou evidenciado pelos resultados deste trabalho.

VELLOSO, L.; PROCKNOR, M.; STRAZZACAPPA, W.; SEKI, K.; MILTENBURG, G. Digestibility and forage production from a pasture of molassesgrass (Melinis minutiflora, Pal de Beauv).
Phase II. Dry scason. Rev Fac.Med.vet Zootec.Univ S.Paulo, 19(1): 87-95, 1982.

SUMMARY : A digestion trial was conducted in order to determinc the nutritive value of molassesgrass (Melinis minutiflora, Pal d Beauv) during the dry season in Pirassununga State of São Piulc. Brazil. Three young crossbred Holstein vs Zebu bulls were kept in cages during seven days for the collection, there were performed after eight-day of adaptation period to the forage. Fresh choppul grass was fed to the animals after 240,300 and 360 days of urass growing periods. Digestible nutrients in the grass were as follows: After 240 days: (DDM-digestible dry material $=12,7 \%$; DP-digestible protein=zero; DEE-digestible etheral extract $=3,3 \%$; DCI $:$ digestible fibers $=20,9 \%$; DNFE-digestible unazotated extract $=$ $20.4 \%$ and TDN-total digestible nutrients $=44.6 \%$. After 300 days: $\mathrm{DDM}=16,2 \% ; \mathrm{DP}=2 \mathrm{ero} ; \mathrm{DEE}=2,4 \% ; \mathrm{DCF}=22,8 \% ; \mathrm{DNFE}=18,5 \%$ and $\mathrm{TDN}=43,7 \%$. After 360 days: $\mathrm{DDM}=26,0 \% ; \mathrm{DP}=z e r o ; \mathrm{DEE}=$ $0,7 \% ; \mathrm{DCF}=23,8 \% ; \mathrm{DNFE}=20,0 \%$ and $\mathrm{TDN}=44,5 \%$.

LNITERMS: Food digestibility* ; Molassesgrass*; Forage production* 
Digestibilidade (aparente) e produção forrageira de um pasto de capim gordura (Melinis minutiflora, Pal de Beauv).

\section{REFERÊNCIAS BIBLIOGRÁFICAS}

1- ANDREASI, F.; PRADA, F.; MENDONÇA JR., C.X.; VEIGA, J.S.M. Levantamento da composição química em plantas forrageiras oriundas de área delimitadas no Estado de São Paulo. Rev.Fac. Med.Vet., São Paulo, 8(1):159-75, 1969.

2- ASSOCIATION OF OFFICIAL AGRICULTURAL CHEMISTS. Official methods of analysis. 9.ed. Washington, 1960. 832p.

3- CARVALHO, L.A.; GARCIA, R.; COELHO DA SILVA, J.F. Teores de matéria seca e proteína bruta no feno do capim gordura (Melinis minutiflora - Pal de Beauv) sob processos de fenação e armazenamento. In: REUNIÃO DA SOCIEDADE BRASILEIRA DE ZOOTECNIA, 16., Curitiba, 1979. Anais. p.355.

4- COELHO DA SILVA, J.F. \& GOMIDE, J.A. Efeito do estádio de maturação sobre o consumo e digestibilidade aparente da matéria seca de três gramíneas tropicais. Rev.Ceres, Viçosa, 13(76): 255.75, 1967.

5- GOIS MENDONÇA, C.A. \& NASCIMENTO JR., D. Composição química de sete forrageiras tropicais em quatro estádios de maturação. Seiva, Viçosa, 34(83):1-8, 1974.

6- JARDIM, W.R. Alimentação do gado leiteiro durante o período da seca. In: SEMINÁRIO DE NUTRIÇÃO DE RUMINANTES, 1., São Paulo, 1960. Anais. 1961 .
7- McDONALD, P.; EDWARDS, R.A.; GREENHALGH, J.F.D. Animal nutrition. 2.ed. Edinburg, Oliver \& Boyd, 1973. 479p.

8- PAULA, R.R.; GOMIDE, J.A.; SYKES, D.J. Influência de diferentes sistemas de corte sobre o capim gordura (Melinis minutiflora, Pal de Beauv). R. Ceres, Viçosa, 14(80):157-85, 1967.

9- PLUT, D.L. \& MELOTTI, L. Estudo dos teores de lignina e de outros componentes químicos nos capins jaraguá e gordura. B.Indústr anim., São Paulo, 23:169-75, 1965/66.

10- ROCHA, G.L. Variedades forrageiras. Zootecnia, São Paulo, 6(1):5-11, 1968.

11- SCHNEIDER, B.H. \& FLATT, W.P. The evaluation of feeds throught digestibility experiments. Athens, University of Georgia Press, 1975. 423p.

12- VELLOSO,L.; PROCKNOR, M.; STRAZZACAPPA, W.; SEKI, K. Digestibilidade (aparente) e produção forrageira de um pasto de capim gordura (Melinis minutiflora, Pal de Beauv). Fase I - Período de verão. Rev.Fac.Med.vet.Zootec.Univ.S. Paulo, 15(1):117-26, 1978.

Recebido para publicação em: 02-03-1982. Aprovado para publicação em: 01-09-1982. 